\title{
4th International Hernia Congress, Berlin 2009
}

\author{
Joint Meeting of the American Hernia Society and the European Hernia Society: \\ 9th to 12th September 2009, Berlin Germany
}

\section{A. N. Kingsnorth}

Received: 19 October 2009 / Accepted: 19 October 2009 / Published online: 8 November 2009

(C) Springer-Verlag 2009

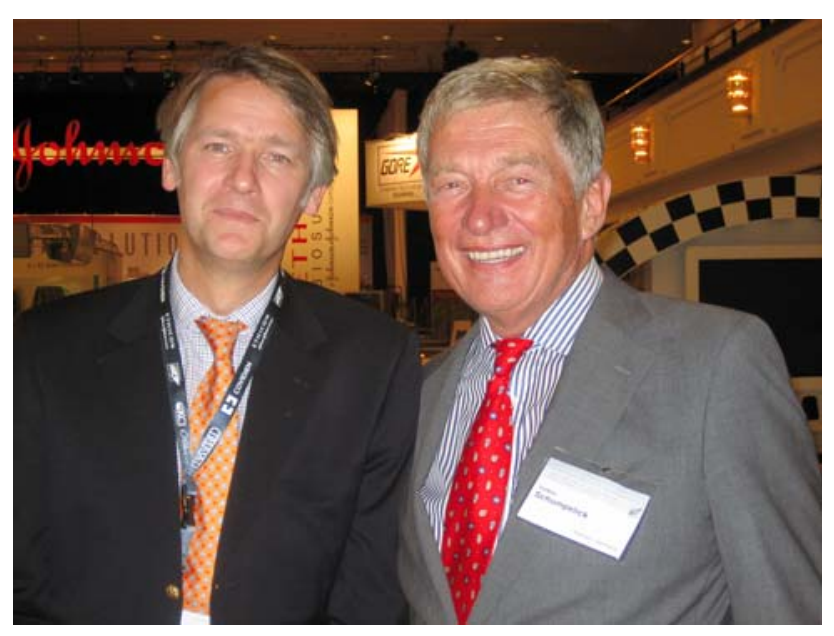

A meeting of outstanding scientific and social content organised by Congress President Professor Volker Schumpelick and a secretariat led by Dr. Joachim Conze took place in the united and revitalised city of Berlin, Germany.

The congress venue in the Maritim Hotel provided an ideal venue for plenary sessions, breakout sessions, poster displays and a hall like an Arabian market, where the sellers and buyers of hernia products dealt, socialised and discussed the various products available. At strategic times in the day, more than 2,000 delegates were provided with drinks, refreshment and fine pastries.

These small comforts, and the satisfaction of a convivial networking area, enabled the delegates to fully appreciate the superb scientific programme. This included the latest information on biological meshes, post-herniorrhaphy pain, mesh fixation, medicolegal aspects of hernia surgery, guidelines, aspects of incisional hernia repair, movie sessions and a unique contribution on humanitarian hernia surgery. More than 200 scientific papers were read and 100 posters presented. Keynote lectures were provided by most of the key opinion leaders from either side of the Atlantic. In addition, all of the major industry providers staged symposia during the breakfast, lunch or afternoon break periods to provide preliminary data and outcome studies for new products. The sessions held in the plenary hall were well attended, with good chairmanship and stimulating discussion.

Befitting such a successful scientific programme, the two organised social events provided delegates with an experience of two of the most eclectic buildings in Berlin. The speakers' dinner took place under the Norman Foster Dome of the Reichstag, from which there was a stunning view over the city of Berlin. The approach to this venue along the former line of the Berlin Wall was a reminder of the amazingly peaceful resolution of the division between the former Eastern and Western parts of this city. The unforgettable gala dinner took place in a concert house at the Gendarmenmarkt. Besides a sumptuous meal, entertainment included a recital on the organ, a comedian for all cultures and a beguiling colourful laser and smoke show.

This congress was wonderful in all respects and, in scientific and social terms, will leave a mark on the memories of the delegates for many years to come.

\footnotetext{
A. N. Kingsnorth $(\bowtie)$

Derriford Hospital, Plymouth PL6 8DH, UK

e-mail: andrew.kingsnorth@phnt.swest.nhs.uk
} 